\title{
Rehabilitation Treatment In Aphasia Caused By Stroke(Review)
}

\author{
Parvane Rahimifar ${ }^{1}$, M ajid Soltani $^{2,3 *}$, Negin M oradi ${ }^{2,3}$ \\ ${ }^{1}$ MSc Speech Therapy, Musculoskeletal Rehabilitation Research Center, Ahvaz Jundishapur University Of M edical \\ Sciences, Ahvaz ,Iran. \\ ${ }^{2}$ M usculoskeletal Rehabilitation Research Center. Ahvaz Jundishapur University Of M edical Sciences, Ahvaz ,Iran. \\ ${ }^{3}$ Dept. of Speech Therapy, Ahvaz Jundishapur University Of M edical Sciences , Ahvaz , Iran. \\ *Corresponding Author: Email: soltani-m@ajums.ac.ir
}

Aphasia is a relatively common language disorder, occurring in about $25 \%$ of all stroke patients. The ultimate aim of aphasia treatment is to improve patients oral and written language abilities and to facilitate their participation in everyday communication. Over the last decades, a range of approaches in aphasia therapy have been introduced, based on cognitive neuropsychological models, psycholinguistic theories, and socio-pragmatic approaches. In view of the range of different approaches and findings of therapy studies, the challenge for therapists is to decide which approach is the most appropriate one for an aphasic individual at a specific stage of recovery.

The Findings showed that, therapy plan for aphasic individuals involves selecting the therapeutic approach most appropriate for dealing with a particular type of disorder, degree of severity, stage of recovery and the extent of the patient's participation in social life. A framework of aphasia treatment is outlined which considers the rehabilitation process at the various stages of recovery, and Different approaches are combined into a comprehensive treatment regimen which differentiates three stages of recovery: the acute, post-acute, and chronic stage. Also ,The intensive therapy in the treatment of language disorders have a great effect, and Brain imaging studies have shown that the linguistic reorganization of a damaged brain is aided by intensive speech therapy even in the chronic phase.

Key words: Aphasia, Rehabilitation, Speech therapy

DOI: $10.7575 /$ aiac.abcmed.ca1.27

A I Published Date: February 2017

Peer-review is under responsibility of the 9th Iranian Stroke Congress.

Published by Australian International Academic Centre, Australia

This published work is open access under the CC BY license.

Available online at www.abcmed.aiac.org.au 